Aletria, Belo Horizonte, v. 29, n. 3, p. 133-149, 2019

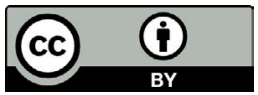

\title{
Perspectivas para uma metaforologia da antropofagia: Blumenberg, Montaigne e Oswald de Andrade
}

\section{Perspectives for an Anthropophagy's Metaphorology: Blumenberg, Montaigne and Oswald de Andrade}

\author{
Patricia Gissoni de Santiago Lavelle \\ Pontifícia Universidade Católica do Rio de Janeiro (PUC-Rio), Rio de Janeiro, Rio \\ de Janeiro / Brasil \\ patricia.g.lavelle@gmail.com
}

Resumo: Ao examinar a antropofagia modernista do ponto de vista de um novo instrumental teórico-metodológico, a metaforologia de Hans Blumenberg, percebe-se que o próprio objeto do estudo crítico-literário se reconfigura. Compreendida como uma metáfora, a antropofagia aparece como uma rede intertextual complexa que se transforma historicamente, atravessando diferentes discussões. Inversamente, uma leitura crítica da metáfora antropofágica permite esclarecer aspectos significativos do próprio instrumento teórico-metodológico, estabelecendo pontes entre metaforologia e antropologia.

Palavras-chave: metaforologia; antropofagia; modernismo brasileiro; Blumenberg; Montaigne; Oswald de Andrade.

Abstract: When we analyse the Brazilian modernist anthropophagy through the perspective of a new theoretical and methodological apparatus, that is Hans Blumenberg's metaphorology, the object of the critical literary studies changes. Accounting the modernist anthropophagy as a metaphor, it becomes a complex intertextual web that changes historically and goes through several discussions. On the other hand, a critical investigation of the anthropophagic metaphor allows us to analyse some interesting aspects of the methodological instrument itself. It also permits us to relate metaphorology to anthropology.

Keywords: metaphorologie; antropophagie; brazilian modernism; Blumenberg; Montaigne; Oswald de Andrade. 


\section{Introdução}

Ao examinar a antropofagia modernista do ponto de vista de um novo instrumental teórico-metodológico, a metaforologia de Hans Blumenberg, percebe-se que o próprio objeto do estudo crítico-literário se reconfigura. Compreendida como uma metáfora teórica, a antropofagia aparece como uma rede intertextual complexa que interage com os debates estéticos e sociais da época, mas também se amplia e transforma historicamente, atravessando diferentes discussões. Afinal, esse novo objeto metafórico ultrapassa o momento modernista, sugerindo um estudo mais exaustivo ainda porvir que incluiria suas retomadas posteriores ao modernismo e poderia chegar até o seu uso contemporâneo, por exemplo, em Eduardo Viveiros de Castro. Inversamente, uma leitura crítica da metáfora antropofágica permite esclarecer aspectos significativos do próprio instrumento teórico-metodológico, estabelecendo pontes entre metaforologia e antropologia.

Tomando a expressão "visage du monde" de Montaigne como caracterização metafórica de um aspecto da própria metáfora, Blumenberg a compreende como uma necessidade humana: a de conferir ao elemento espacial uma significância que o associa a valores humanos, atribuindo, por exemplo, sorrisos a um prado.

O que não aparece entre as propriedades de um prado do ponto de vista objetivo, mas ainda não é um acréscimo da fantasia subjetiva de um observador, que poderia reconhecer na superfície deste os contornos de um rosto humano (brincadeira que faz parte do espetáculo das estalagmites de uma gruta) é conservado pela metáfora. Esta é capaz, na medida em que situa o prado no inventário de um mundo vivido humano, onde não apenas palavras e signos, mas também as próprias coisas tem significações cujo arquétipo antropogênico pode ser o rosto humano com sua incomparável significação de estar situado. A metáfora para este teor de sentido da metáfora foi dada por Montaigne: le visage du monde. ${ }^{1}$

\footnotetext{
1 "Was in den Eigenschaften einer Wiese unter objeltivem Aspekt nicht vorkommt, aber auch nicht die subjektiv-phantastische Zutat eines Betrachters ist, der nur für sich die Konturen eines menschlichen Gesichts aus der Oberfläche der Wiese herauslesen könnte (ein Spiel, das zur Besichtigung von Tropfsteinhöhlen gehört), wird von der Metapher
} 
Essa interessante alusão a Montaigne parece repousar, entretanto, sobre uma inexatidão no que concerne ao eixo conceitual. Afinal, com essa expressão, Montaigne não visava a caracterização da metáfora. No contexto de seus Ensaios, ${ }^{2}$ ela designa o conjunto de hábitos e costumes que fazem o mundo de cada cultura. As viagens marítimas do Renascimento e os contatos que delas resultaram com universos culturais não europeus são, neste sentido, muito importantes em sua obra. Entretanto, remetendo à infinita plasticidade ${ }^{3}$ humana, à pluralidade das configurações culturais da imaginação, os rostos do mundo de Montaigne têm íntima relação com os de Blumenberg. Assim, a referência à metáfora de Montaigne não corresponde a um engano numa reconstrução conceitual, mas a um deslocamento do sentido metafórico numa nova transposição, que não é desprovida de relação com o primeiro "transporte". Ora, o uso deslocado que Blumenberg faz desta construção metafórica é significativo, pois diz respeito à articulação profunda entre seu projeto metaforológico e suas reflexões antropológicas.

Como a metáfora se articula à plasticidade humana que não apenas está na origem da pluralidade dos mundos culturais, mas é também capaz de representar os "rostos do mundo" do passado e novos "rostos" ainda por vir? Essa interrogação nos levará a examinar a historicidade da construção metafórica que, no "Manifesto Antropófago", de Oswald de Andrade, se apoia sobre considerações antropológicas contidas no ensaio "Dos Canibais", de Montaigne. Metáfora de uma concepção da identidade cultural que se funda sobre a relação com a alteridade, a antropofagia oswaldiana nos leva tanto ao rosto do mundo de Blumenberg quanto ao de Montaigne.

festgehalten. Sie leistet dies, indem sie die Wiese dem Inventar einer menschlichen Lebenswelt zuweist, in der nicht nur Worte und Zeichen, sondern die Sachen selbst 'Bedeutungen' haben, deren anthropogenetischer Urtypus das menschliche Gesicht mit seiner unvergleichlichen Situationsbedeutung sein mag. Die Metapher für diesen Sinngehalt der Metapher hat Montagne gegeben: le visage du monde" (BLUMENBERG. Schiffbruch mit Zuschauer, p. 89, tradução minha).

${ }^{2}$ Cf. MONTAIGNE. Essais.

${ }^{3}$ Sobre a noção de plasticidade ligada ao conceito de imaginação: BOURIAU. Qu'estce que l'imagination?, p. 110-111. 


\section{Da metáfora como "rosto do mundo" aos "rostos do mundo" de Montaigne}

Contra o ideal cartesiano de uma língua teórica perfeitamente conceitual, e, portanto, a-histórica, Blumenberg evoca uma lógica da imaginação e retoma a problemática kantiana da apresentação simbólica das ideias para propor a investigação do papel das metáforas no discurso teórico. Procura, assim, mostrar que estas construções poéticas constituem não apenas antecipações de formulações sistemáticas posteriores, mas que algumas delas, as metáforas ditas "absolutas", são definitivas, pois intransponíveis em termos conceituais. Mas Blumenberg não convoca a metáfora contra o conceito, ele procura investigar as relações complexas entre elaborações conceituais e metafóricas. Considerada como uma construção discursiva complexa e intertextual, e não apenas como uma simples transferência que se efetuaria no nível da palavra, a metáfora constitui, segundo o autor, um instrumento indispensável de toda elaboração filosófica, complementar ao conceito.

O posfácio de Naufrágio com espectador, ${ }^{4}$ que contém a referência a Montaigne, indica uma mudança de ponto de vista no projeto inicial da metaforologia. Esta não é mais apresentada apenas como um exame histórico das metáforas teóricas, mas passa a incluir a investigação das correlações não conceitualizáveis que se articulam às exigências da razão ultrapassando os limites do instrumento conceitual. Ora, segundo a Teoria da não-conceitualidade, volume também dos anos setenta no qual Blumenberg elabora uma releitura detalhada do $\$ 59$ da Crítica da faculdade de julgar, de Kant, as metáforas são tanto mais radicais quanto mais os contextos conceituais nos quais elas aparecem são indeterminados. Assim, a apresentação das ideias mais fundamentais da razão engendra necessariamente metáforas absolutas que vêm se articular ao instrumento conceitual, mas permanecem irredutíveis à conceitualidade.

Na perspectiva desta teoria da não-conceitualidade, as metáforas são consideradas em sua relação com o mundo da vida, isto é, a trama dos modos de sentir e pensar que constitui o horizonte não tematizado de onde cada afirmação se destaca. Assim, Blumenberg as compreende como "fósseis-condutores vindos de uma camada arcaica do processo

\footnotetext{
${ }^{4}$ BLUMENBERG. Schiffbruch mit Zuschauer.
} 
da curiosidade teórica". ${ }^{5}$ Reclamando um estado original de não diferenciação entre teoria e poesia, as metáforas estariam, portanto, tanto em relação com nossas predisposições poéticas quanto com o impulso teórico ainda não trabalhado pela língua especializada dos filósofos. Assim, segundo Blumenberg, elas remetem ao entrecruzamento, no mundo da vida, dos modos de pensamento filosófico e literário, isto é, a uma origem comum à criação poética e ao questionamento teórico.

Segundo Blumenberg, Montaigne fornece a metáfora correspondente a esta compreensão da própria construção metafórica: "o rosto do mundo". Pois, de acordo com ele, o movimento realizado pela operação metafórica, e ilustrado pelo exemplo clássico do "prado que ri", deve ser compreendido como a exigência de conferir um rosto ao mundo. Este gesto, que visa integrar a alteridade e a diversidade radicais no mundo vivido, conferindo um valor simbólico aos elementos mais exteriores da experiência, aparece como a estratégia fundamental da razão em sua aspiração à unidade e à totalidade.

Neste contexto, a referência a Montaigne é significativa, embora pareça assentar sobre um engano. Pois, nos Ensaios, a expressão "rosto do mundo" não designa a metáfora. Esta concerne ao conjunto de costumes, hábitos, crenças, normas, etc., que constituem o "rosto", sempre singular, sob o qual o mundo aparece aos indivíduos numa dada cultura. Dito de outro modo, por "rosto do mundo", Montaigne designa a maneira como cada conjunto cultural "faz mundo". Assim, tematiza a infinita plasticidade humana, isto é, a potência da imaginação. Nesta perspectiva, o ensaísta sugere que as leis da consciência que parecem naturais (e, portanto, universalizáveis, racionais) nascem na realidade da plasticidade imaginativa inscrita nos costumes.

Montaigne afirma que as leis da consciência não são universais, pois não nascem da natureza, mas são o produto de costumes nos quais o "rosto do mundo" se apresenta a nós desde o nascimento. Leitor atento de Giovanni Francesco Pico della Mirandola, ele considera também que a força da imaginação permite que nos arranquemos ao nosso próprio "rosto do mundo", possibilitando a projeção de si no outro, e, portanto, a identificação com outros costumes, de outros povos e épocas.

\footnotetext{
5 "Metaphern sind in diesem Sinne Leitfossilien einer archaischen Schicht des Prozesses der theoretischen Neugierde [...]" (BLUMENBERG. Schiffbruch mit Zuschauer, p. 87, tradução minha).
} 
Retomando no Renascimento as teses sobre a imaginação que Aristóteles esboça em seu tratado De Anima, Mirandola encontra a faculdade imaginativa no conjunto de operações do espírito humano. Entretanto, conferindo uma inflexão nova às considerações aristotélicas, ele relaciona a problemática da imaginação à infinita plasticidade humana. É esta relação entre a capacidade de produzir imagens e a ausência de fixação do humano que será desenvolvida por Montaigne. ${ }^{6}$

Segundo Montaigne, no que concerne o estudo dos usos e ações, os testemunhos fabulosos ou ficcionais seriam tão pertinentes quanto os supostamente verídicos pois ambos constituem desenvolvimentos desta capacidade de produzir imagens que é responsável pela infinita plasticidade humana. Para ele, o valor do homem não está em sua submissão a uma racionalidade universal normativa - como em Descartes - mas na exploração da fantasia como instrumento de transformação. Assim, a exploração dos recursos do ficcional e o uso de imagens poéticas, abundantes no estilo dos Ensaios, se inscrevem na historicidade intrínseca a uma verdade polimorfa, construída pela infinita plasticidade humana.

Designando a pluralidade de configurações culturais da imaginação, os rostos do mundo de Montaigne estão em relação com os de Blumenberg. $\mathrm{O}$ falso engano do segundo remete, efetivamente, à articulação profunda entre o projeto metaforológico e uma problematização de tipo antropológico. Ora, o fragmento publicado postumamente como uma espécie de posfácio a sua Teoria da não-conceitualidade permite compreender essa relação. ${ }^{7}$ Pois, explorando ele mesmo uma espécie de fábula científica, Blumenberg aí indica as implicações antropológicas da constituição das funções metafórica e conceitual.

De acordo com a narrativa construída por Blumenberg, os primeiros humanos pré-históricos abandonam o domínio imediato da percepção no momento em que se colocam de pé, o que implica uma extensão do campo visual. Simultaneamente ao alargamento súbito do horizonte de seus sentidos, eles se distanciam da experiência imediata, o que lhes permite diferir reações e prevenir. Se descolando da percepção imediata, os primeiros humanos podem, segundo ele, representar objetos ausentes - e não apenas aqueles dos quais necessitam na luta pela

\footnotetext{
${ }^{6} \mathrm{Cf}$. a leitura de Giovanni Francesco Pico della Mirandola proposta por Bouriau (2003) em Qu'est-ce que l'imagination?.

${ }^{7}$ BLUMENBERG. Teoria da não-conceitualidade.
} 
sobrevivência e que procuram capturar, mas também os que desejam. Nesta perspectiva, o conceito é compreendido como um tipo de armadilha destinado à captura de objetos ausentes enquanto a metáfora remete ao horizonte mais longínquo de outros objetos, associados aos primeiros, mas que se encontram além das necessidades de sobrevivência.

Assim, quando os indivíduos pré-históricos imaginados por Blumenberg desenham nas paredes das cavernas, eles se distanciam da busca incessante de satisfazer suas necessidades imediatas para conferir significância ao espaço. É este movimento que pode ser compreendido metaforicamente como a atribuição de um rosto ao mundo. Pois desenhar objetos ausentes não implica apenas a capacidade de representar conceitualmente tais objetos, mas também a de cristalizar em torno deles estes desejos que remetem à esfera na qual Platão colocará as ideias e Kant atribuirá reflexivamente à razão. Neste gesto, os primeiros humanos se inventam a si mesmos como seres de cultura. Seu descolamento da natureza estaria, portanto, ligado a esta capacidade plástica que é o correlato do impulso teórico - o que é próprio ao humano é precisamente não ter uma natureza ou um caráter próprio, mas se afastar da esfera da necessidade para se inventar livremente.

Ora, embora Blumenberg não o tematize, o que ele chama de "exercício muscular da liberdade" no movimento de simbolização se efetua de maneira múltipla, numa pluralidade potencialmente infinita de "rostos" culturais do mundo. De acordo com sua teoria da nãoconceitualidade, a análise da construção metafórica permite se orientar na simbolização disseminada de um mundo humano, onde não apenas as palavras, mas também as coisas têm uma significância que não se esgota com sua objetivação e pode ser compreendida metaforicamente como a exigência de lhes conferir um rosto. Assim, a caracterização da metáfora como rosto do mundo se aproxima efetivamente da noção antropológica de rosto do mundo em Montaigne. Esta plasticidade infinitamente polimorfa não apenas faz a pluralidade dos conjuntos culturais, mas constitui ainda o que nos permite representar rostos do mundo passados e outros, novos, presentes em outro lugar ou ainda por vir. A aproximação entre Blumenberg e Montaigne em torno da noção de "rosto do mundo" nos conduz, portanto, a fazer um passo a mais para nos interrogarmos sobre a relação entre a invenção metafórica e a problemática antropológica da identidade cultural e da pluralidade das culturas. 
Para fazê-lo, examinaremos a historicidade de uma construção metafórica elaborada a partir de materiais antropológicos contidos no ensaio de Montaigne sobre os "canibais", entre outros textos. Tratase da invenção literária de uma metáfora teórica, a da antropofagia cultural, no contexto vanguardista do modernismo brasileiro. Essa investigação histórica nos permitirá inverter o ponto de vista teórico inicialmente adotado para observar como um "rosto do mundo", no sentido de Montaigne, pode se converter numa metáfora que nos remete à pluralidade e à alteridade cultural no interior da ideia de cultura e de identidade cultural, tornando-se, portanto, um "rosto do mundo" no sentido de Blumenberg, isto é, uma construção metafórica.

Este duplo "rosto do mundo" nasce da transposição metafórica, efetuada pelo escritor Oswald de Andrade em seu "Manifesto antropófago", de 1928, da imagem do ritual guerreiro canibal, praticado pelos índios que habitavam as costas brasileiras até o século XVI, para uma reflexão sobre a identidade cultural no horizonte de um projeto periférico de modernidade literária. Oswald de Andrade concebe, efetivamente, uma metáfora capaz de substituir a da "raiz" com o objetivo de pensar o que os escritores modernistas chamavam de "brasilidade", isto é, a "essência" cultural nascente e bastante indeterminada do Brasil e dos brasileiros.

Ora, essa "brasilidade" era, sobretudo, uma interrogação e um projeto que as vanguardas literárias e artísticas se propunham a realizar de diferentes maneiras. O problema contra o qual os diversos programas se confrontavam era o de uma modernidade "de importação", que se contentava em atualizar a produção artística pela imitação de modelos europeus. Criticando as formas artísticas tradicionais, fundadas sobre a mimésis clássica, o discurso modernista, que encontrava inspiração nas vanguardas europeias da mesma época, procurava, entretanto, se emancipar também da imitação cultural. Assim, a via da modernidade artística se confundia com a busca da "essência" brasileira, daquilo que constituiria a especificidade da contribuição do Brasil para modernidade internacional. E no contexto destes debates em torno da "brasilidade" que um certo rosto antropofágico do mundo aparece como uma metáfora teórica absoluta, frequentemente retomada e atualizada ao longo do século $\mathrm{XX}$ e, ainda hoje, na obra de Eduardo Viveiros de Castro. ${ }^{8}$

\footnotetext{
${ }^{8} \mathrm{Cf}$. VIVEIROS DE CASTRO. Metafisicas canibais - elementos para uma antropologia pós-estrutural.
} 


\section{Antropofagia: do ritual guerreiro à metáfora teórica}

Entre 1917 e 1924, a preocupação central daqueles que, no Brasil, se diziam modernistas era a renovação estética da produção artística nacional através da recepção de novas proposições formais vindas das vanguardas europeias. Tratava-se, como afirma Oswald de Andrade em seu "Manifesto da Poesia Pau-Brasil" (de 1924), de acordar o "relógio império da literatura nacional". ${ }^{9}$ Entretanto, este texto programático publicado em 1924 situa a si mesmo num segundo momento no qual se coloca um outro problema: o da "brasilidade" do Brasil. De um a outro, o questionamento da imitação se desloca da contestação vanguardista do quadro clássico da representação - a arte como "cópia" do real ou da natureza - à crítica da imitação de modas e modelos europeus importados. Assim, será preciso recusar uma modernização de importação, na qual a produção artística e literária se contentaria em seguir com atraso as novas tendências europeias, para pensar a contribuição propriamente brasileira à "civilização universal", isto é, uma arte e uma literatura "de exportação". singular:

É esta problemática que Mário de Andrade sintetiza numa sintaxe

Problema atual. Problema de ser alguma coisa. E só se pode ser, sendo nacional. Nós temos o problema atual, nacional, moralizante, humano de brasileirar o Brasil. [...] E nós só seremos universais o dia em que o coeficiente brasileiro nosso concorrer para a riqueza universal. ${ }^{10}$

Mas o que é o brasileiro? Como definir, identificar ou quantificar esse "coeficiente brasileiro nosso" de que fala Mário de Andrade? A partir de 1923-1924, a questão da "brasilidade" se encontra no centro de todos os debates artísticos e literários. A esta busca identitária responde uma certa inclinação para o primitivismo que, apesar de também encontrar inspiração no interesse das vanguardas europeias pela arte de povos ditos "selvagens", procura a brasilidade autêntica na cultura popular, onde as contribuições indígenas e/ou africanas desfariam a inautenticidade da emulação colonial e pós-colonial. Entretanto, é em relação à questão

\footnotetext{
${ }^{9}$ ANDRADE. A Utopia Antropofágica, p. 65.

${ }^{10} \mathrm{Cf}$. a carta de Mário de Andrade ao poeta modernista franco-brasileiro Sergio Milliet (JARDIM DE MORAIS. A brasilidade modernista. sua dimensão filosófica, p. 52).
} 
da "brasilidade" que as posições estéticas e ideológicas começam a se distinguir umas das outras no interior do movimento modernista.

Estudioso do Romantismo alemão, Mario de Andrade encontra uma resposta à questão identitária no estudo, coleção e valorização de um conjunto de materiais vindos da cultura popular. Para isso, realiza inúmeras viagens etnográficas e, a partir dos anos trinta, propõe ações institucionais concretas. ${ }^{11} \mathrm{O}$ repertório de formas autenticamente brasileiras assim obtido ficaria à disposição dos artistas modernos e poderia constituir as bases de uma identidade cultural concebida substancialmente, como um patrimônio comum não distorcido pelos mecanismos miméticos de alienação colonial e pós-colonial. Por outro lado, o grupo "verde-amarelo", federado por Plinio Salgado e de inspiração politicamente conservadora, confere um sentido étnico à referência ao índio, considerando a essência da nacionalidade com a herança de um substrato biológico, psíquico e espiritual, isto é, como um conceito substancial reificado. ${ }^{12}$

Esboçada já no "Manifesto da Poesia Pau-Brasil", a noção de identidade visada pela metáfora antropofágica se distingue destas duas outras concepções da "brasilidade". Pois, na perspectiva desta metáfora teórica, a identidade não se funda sobre uma coleção ou um conjunto de elementos positivos e definíveis, mas sobre uma função complexa de retomada, assimilação e transformação, isto é como "digestão", metáfora que aparece neste manifesto de 1924:

A reação contra todas as indigestões de sabedoria. O melhor de nossa tradição lírica. O melhor de nossa demonstração moderna.

Apenas brasileiros de nossa época. O necessário de química, de mecânica, de economia e de balística. Tudo

\footnotetext{
${ }^{11}$ Sobre a referência aos românticos alemães e sobre a ação institucional de Mário de Andrade como diretor do Departamento de Cultura da Prefeitura de São Paulo, cf. JARDIM DE MORAIS. Eu sou trezentos. Mário de Andrade: vida e obra. Sobre a noção de brasilidade de cunho patrimonial concebida por Mario de Andrade, cf. ANDRADE. Ensaio sobre a música brasileira.

${ }^{12}$ Eduardo Jardim de Morais mostra que o grupo dos "antropófagos" e o grupo "verdeamarelo" representam duas tendências divergentes na compreensão da identidade brasileira que, embora tenham como ponto de partida comum a referência ao elemento indígena e a crítica das ideias do escritor Graça Aranha, constituirão posições políticas, sociais e estéticas completamente opostas. Cf. JARDIM DE MORAIS. A brasilidade modernista: Sua dimensão filosófica.
} 
digerido. Sem meeting cultural. Práticos. Experimentais. Poetas. Sem reminiscências livrescas. Sem comparações de apoio. Sem pesquisa etimológica. Sem ontologia. ${ }^{13}$

De acordo com o programa da poesia "pau-brasil", a rejeição do modelo de modernidade de importação que, no século XIX, mima nos trópicos a indigestão histórica denunciada por Nietzsche não exclui a historicidade. ${ }^{14}$ Segundo Oswald, não se trata de fazer o inventário erudito dos materiais culturais populares, como queria Mario de Andrade, mas de "digerir" historicamente os materiais mais diversos. Nesta perspectiva, a reivindicação de um certo primitivismo nativo se associa a um olhar histórico-crítico para o passado - olhar capaz de acolher a alteridade no seio de uma identidade que estaria sempre em construção num processo criativo, plástico. Assim, não busca no passado as raízes ou heranças que seriam capazes de fundar substancialmente a identidade, mas procura criticar a história num fazer poético que, utilizando e ironizando materiais históricos, como relatos de viajantes da época colonial, apresenta a identidade como função ou processo. ${ }^{15}$

Essa compreensão da identidade cultural como assimilação e transformação da relação com a alteridade - processo sempre inacabado implicando uma crítica da história -, se radicaliza no final dos anos vinte com o "Manifesto Antropófago". Se o "Manifesto da Poesia Pau-Brasil"

${ }^{13}$ Cf. "Manifesto da Poesia Pau-Brasil" (ANDRADE. A utopia antropofágica).

${ }^{14}$ A indigestão de sabedoria de Oswald retoma provavelmente uma metáfora tecida por Nietzsche na Segunda consideração intempestiva. Da utilidade e desvantagem da história para a vida. Segundo Nietzsche, o homem moderno, nutrido de cultura histórica, teria o estômago sobrecarregado com uma massa enorme de conhecimentos indigestos que nele se entrechocam e cujos "barulhos" denunciariam a oposição característica da modernidade - e desconhecida dos povos antigos - entre interioridade e exterioridade. Nesta construção metafórica, o filósofo concebe a imitação servil ou a caricatura moderna dos modelos do passado como um tipo de indigestão histórica. A potência criadora ou a plasticidade de uma cultura - sua capacidade de se nutrir de épocas, costumes, filosofias e conhecimentos estrangeiros, transformando-os - seria assim compreendida através da metáfora da digestão, única função capaz de reconciliar a forma exterior e o conteúdo interior. Cf. NIETZSCHE. Segunda consideração intempestiva: Da utilidade e desvantagem da história para a vida.

${ }^{15}$ Cf. ANDRADE. Poesia Pau-Brasil, p. 73-97. Neste livro de 1925, há uma longa série de poemas inteiramente construídos a partir de relatos de viajantes que estiveram no Brasil nos primeiros séculos da colonização. 
se inicia com uma enumeração de imagens da paisagem brasileira, este manifesto de 1928 se abre com uma visada universal que problematiza e relativiza a própria referência aos Tupis:

Só a ANTROPOFAGIA nos une. Socialmente. Economicamente. Filosoficamente.

Única lei do mundo. Expressão mascarada de todos os individualismos, de todos os coletivismos. De todas as religiões. De todos os tratados de paz.

Tupi, or not tupi that is the question. ${ }^{16}$

Marcando uma distância irônica em relação à identificação com os Tupis numa primeira pessoa do plural que se encontra, entretanto, no centro de seu texto, Oswald de Andrade chama a atenção para o caráter construído de sua antropofagia - e, portanto, para sua metaforicidade. Reconstruída a partir dos relatos de viajantes europeus do século XVI que encontraram índios antropófagos nas costas brasileiras e sobretudo do ensaio "Dos Canibais" de Montaigne, a imagem do ritual antropófago coloca o problema da cultura em geral e da identidade cultural brasileira em particular. É a articulação complexa dessa imagem a este questionamento que constitui o que aqui chamamos de metáfora teórica. Com esta metáfora, Oswald, que também se refere a Freud, ${ }^{17}$ procura transformar o "tabu", o interdito do canibalismo ameríndio, em "totem", isto é, em símbolo de uma identidade sociocultural.

Esta construção metafórica que visa converter o "tabu" em "totem" se apoia sobre o "rosto do mundo" que Montaigne esboça ao descrever os costumes dos habitantes do lugar "où Villegagnon prit terre". ${ }^{18}$ Efetivamente, ele descreve os costumes dos índios que viviam em torno da Baia da Guanabara a partir sobretudo dos relatos de viajantes franceses de sua época. Ora, se o ensaio "Dos Canibais" começa por considerar que este povo seria mais próximo das leis naturais, estando, portanto, impregnado de uma "ingenuidade original", este é, entretanto, julgado a partir de uma certa virtude guerreira greco-latina.

\footnotetext{
${ }^{16}$ ANDRADE. A Utopia Antropofágica, p. 67.

${ }^{17}$ FREUD. Totem und tabu: Einige Übereinstimmungen im Seelenleben der Wilden und der Neurotiker.

${ }^{18}$ MONTAIGNE. Essais, p. 200. Essa expressão de Montaigne é citada em francês por Oswald de Andrade no "Manifesto antropófago".
} 
Esse anúncio do quadro dos costumes canibais, que Montaigne passa em seguida a "pintar", remete também às ficções poéticas da Era de Ouro ou às utopias filosóficas (ele se refere diretamente à República de Platão). De fato, o "rosto do mundo" constituído por estes costumes estranhos funciona como uma imagem ficcional (ou utópica) destinada à reflexão, por contraste, sobre os desejos e costumes da sociedade europeia do Renascimento. Nesse sentido, Montaigne descreve uma comunidade humana primitiva que se define sobretudo pelas características que não tem:

[...] nenhuma espécie de tráfico; nulo conhecimento de letras; nula ciência de números; [...] nulo uso de serviço, de riqueza ou de pobreza; nulos contratos; nulas sucessões; nulas partilhas; nulas ocupações, apenas distrações; nulo respeito do parentesco além do comum; nulas roupas [...]. ${ }^{19}$

A sucessão de negativas é seguida pela afirmação da abundância natural em torno de uma comunidade na qual a própria ideia de excedente não tem sentido, e, portanto, na qual as guerras, embora numerosas, não têm outro objetivo nem buscam outro troféu além da honra da própria vitória. É no contexto desta virtude guerreira, pintada um pouco à moda antiga, que Montaigne insere a descrição do ritual antropófago:

Depois de ter por longo tempo tratado bem seus prisioneiros, e de todas as comodidades que eles podem conceber, aquele que é o mestre, faz uma grande assembleia de seus conhecidos; ele prende uma corda em um dos braços do prisioneiro, pela ponta da qual o segura, [...] e ao mais caro dentre os seus amigos dá o outro braço para segurar do mesmo jeito; e eles dois, na presença de toda a assembleia, o assomam a golpes de espada. Isto feito, eles o assam e o comem em comum, e dele enviam pedaços aos seus amigos que estão ausentes. E não é, como alguns pensam, para se nutrir, assim como faziam antigamente os Citas; é para representar uma extrema vingança. ${ }^{20}$

19 "aucune espece de trafique; nul cognoissance de lettres; nulle science des nombres; [...] nul usage de service, de richesse ou de pauvreté; nuls contrats; nulles successions; nuls partages; nulles occupations qu'oysives; nul respect de la parenté que commun; nuls vestiments [...]" (MONTAIGNE. Essais, p. 204, tradução minha).

20 "Après avoir long temps bien traité leurs prisonniers, et de toutes les commoditez dont ils se peuvent aviser, celuy qui en est le maistre, faict une grande assemblée 
Segundo Montaigne, o objetivo dessa antropofagia ritual não é a nutrição, mas uma "representação", a de uma "vingança suprema". Entretanto, se o guerreiro inimigo pede graça, se admite a vitória do outro, é liberado; apenas aqueles que preferem a morte à covardia são comidos:

Eles não pedem a seus prisioneiros outro resgate além da confissão e reconhecimento de serem vencidos; mas não se encontra nenhum, em todo um século, que não prefira a morte do que ceder, que seja por contenção ou de palavra, um único ponto de uma grandeza de coragem invencível; não se vê nenhum que não prefira ser morto e comido do que simplesmente requerer não o ser. ${ }^{21}$

Do ponto de vista da representação desta virtude guerreira, é significativa a evocação por Montaigne de um canto no qual o guerreiro vencido lembra, no momento ritual de sua execução, que ele próprio se nutriu da carne dos antepassados daqueles que estão prestes a devorá-lo:

Esses músculos, diz ele, esta carne e estas veias, são as suas, pobres loucos que vocês são; não reconhecem que a substância dos membros de seus ancestrais nela se encontra ainda: saboreiem bem, vocês aí encontrarão o gosto de sua própria carne.” Invenção que não cheira de modo algum à barbárie. ${ }^{22}$

de ses cognoissans; il attache une corde à l'un des bras du prisonnier, par le bout de laquelle il le tient, [...] et donne au plus cher de ses amis l'autre bras à tenir de mesme; et eux deux, en présence de toute l'assemblée, l'assomment à coups d'espée. Cela faict, ils le rostissent et en mangent en commun et en envoient des lopins à ceux de leurs amis qui sont absents. Ce n'est pas, comme on pense, pour se nourrir, ainsi que faisaient anciennement les Scythes; c'est pour représenter une extrême vengeance." (MONTAIGNE. Essais, p. 207, tradução minha).

21 "Ils ne demandent à leur prisonniers autre rançon que la confession et recoignaissance d'estre vaicus; mais il ne s'en trouve pas un, en tout un siècle, qui n'ayme mieux la mort que de relascher, ny par contenance, ny de parole un seul poinct d'une grandeur de courage invincible; il ne s'en void aucun qui n'ayme mieux estre tué et mangé, que de requerir seulement de ne l'estre pas" (MONTAIGNE. Essais, p. 209, tradução minha). 22 "“Ces muscles, dit-il, cette chair et ces veines, ce sont les vostres, pauvres fols que vous estes; vous ne recognoissez pas que la substance des membres de vos ancêtres s'y tient encore: savourez-les bien, vous y trouverez le goust de vostre propre chair'. Invention qui ne sent aucunement la barbarie" (MONTAIGNE. Essais, p. 211, tradução minha). 
Relembrando seus próprios inimigos comidos no passado, o guerreiro vencido procura relativizar a vitória daqueles que se preparam para devorá-lo: eles encontrarão em sua carne o gosto da sua própria, consumida no passado por ele. O ritual antropofágico implica assim a reconstrução simbólica da identidade da comunidade num processo temporal marcado pelas trocas com o outro. A coesão do grupo é reforçada por essa "vingança suprema" que consiste em comer um inimigo que outrora comeu seus ancestrais.

Oswald de Andrade retoma este esquema simbólico ao transformar a antropofagia ritual praticada pelos índios numa metáfora teórica. Associando Montaigne a Freud, sua construção metafórica opera uma torção no esquema da devoração do pai simbólico que, de acordo com o mito cientifico elaborado em Totem e tabu, estaria na origem do banquete totêmico. Segundo Totem e tabu, que constitui uma referência importante para a antropofagia oswaldiana, bem como para outras correntes de vanguarda brasileiras e europeias que valorizam o primitivo e o inconsciente, a refeição ritual na qual o animal totem, que normalmente não deve ser morto ou consumido pelos membros do seu clã, é sacrificado e servido num banquete, simboliza o assassinato e a devoração do pai despótico da horda primitiva pela fratria oprimida e excluída, evento que teria ocorrido no momento arcaico da passagem entre um agrupamento animal em torno de um macho dominante a uma sociedade humana. Partindo da narrativa deste canibalismo originário que constitui, claro, uma ficção científica, Freud interpreta a refeição totêmica como um reforço da identidade do grupo através da distribuição simbólica do corpo e de aspectos positivos do poder do pai entre os indivíduos. A semelhança mágica entre os membros da tribo totêmica é assim renovada, pois a ligação de cada um com a figura paterna arcaica é intensificada, de modo metonímico, pela absorção ritual de uma parte do animal que a simboliza.

A metáfora teórica elaborada por Oswald de Andrade opera uma síntese entre o canibalismo totêmico de Freud e o "rosto do mundo" dos índios descritos por Montaigne. Na configuração complexa da imagem do ritual antropófago, que está na base da metáfora teórica da antropofagia cultural, o ancestral simbólico devorado é o de uma outra tribo. A fundação da identidade do grupo não se faz pela partilha de uma origem comum ou de uma "raiz" fundadora que garantiria a semelhança entre os diferentes "ramos". 
"Contra as elites vegetais. Em comunicação com o solo", ${ }^{23}$ escreve Oswald no "Manifesto Antropófago", em oposição aberta à metafórica da "raiz", ou das "raízes" no plural, explorada por seu contemporâneo, o escritor Graça Aranha. ${ }^{24}$ Transformando a imagem "tabu" do ritual antropófago em "totem" metafórico modernista, Oswald de Andrade descarta uma compreensão da identidade como fundação ou origem comum para fazê-la assentar sobre um gesto que implica a historicidade da relação ao outro.

Ingestão e digestão (metafóricas) do outro fundam, segundo o "Manifesto Antropófago", não apenas a "brasilidade", mas qualquer identidade cultural. Assim, trata-se da metáfora de um gesto ou de uma prática: a antropofagia é um fazer que coloca em cena a historicidade da relação à alteridade. Opondo-se a toda concepção substancial da identidade cultural, esta corresponde a uma representação funcional do conceito de cultura. Incorporação da relação ao outro na elaboração identitária, a antropofagia oswaldiana apresenta a cultura como uma dinâmica funcional: "Só me interessa o que não é meu. Lei do homem. Lei do antropófago." ${ }^{25}$ Surgida no contexto histórico de um projeto de vanguarda no interior de uma modernidade periférica, na qual a relação com o outro se coloca dramaticamente em cena, a metáfora da "antropofagia cultural" apresenta a pluralidade implicada no próprio conceito de cultura.

\section{Referências}

ANDRADE, M. Ensaio sobre a música brasileira. São Paulo: Vila Rica; Brasília: INL, 1972.

ANDRADE, O. A Utopia Antropofágica. São Paulo: Editora Globo, 2011. (Obras completas: Oswald de Andrade).

ANDRADE, O. Poesia Pau-Brasil. In: . Poesias reunidas. Rio de Janeiro: Civilização Brasileira, 1974. (Obras Completas: v. VII).

BLUMENBERG, H. Schiffbruch mit Zuschauer. Frankfurt/Main: Suhrkamp, 1979.

\footnotetext{
${ }^{23}$ ANDRADE. A Utopia Antropofágica, p. 70.

${ }^{24}$ Cf. GRAÇA ARANHA. A Esthetica da vida.

${ }^{25}$ ANDRADE. A Utopia Antropofágica, p. 67.
} 
Aletria, Belo Horizonte, v. 29, n. 3, p. 133-149, 2019

BLUMENBERG, H. Teoria da não-conceitualidade. Tradução de Luiz Costa Lima. Belo Horizonte: Editora UFMG, 2015.

BOURIAU, C. Qu'est-ce que l'imagination? Paris: Vrin (Chemins Philosophiques), 2003.

FREUD, S. Totem und tabu: Einige Übereinstimmungen im Seelenleben der Wilden und der Neurotiker. Londres: Imago, 1940.

GRAÇA ARANHA, J. P. A Esthetica da vida. Rio de Janeiro: Livraria Garcia, 1921.

JARDIM DE MORAIS, E. A brasilidade modernista: sua dimensão filosófica. Rio de Janeiro, Graal, 1978.

JARDIM DE MORAIS, E. Eu sou trezentos. Mário de Andrade: vida e obra. Rio de Janeiro: Edições de Janeiro, 2015.

MONTAIGNE, M. Essais. In: Gallimard, 1967. (Bibliothèque de la Pléiade). . Euvres complètes. Paris:

NIETZSCHE, F. Segunda consideração intempestiva: da utilidade e desvantagem da história para a vida. Tradução de Marco Antônio Casanova. Rio de Janeiro: Relume Dumará, 2003.

VIVEIROS DE CASTRO, E. Metafisicas canibais - elementos para uma antropologia pós-estrutural. São Paulo: n-1 Edições, 2015.

Recebido em: 25 de janeiro de 2019.

Aprovado em: 20 de agosto de 2019. 